$\begin{array}{ll} & \text { Etnográfica } \\ \text { etnográfica } & \text { Revista do Centro em Rede de Investigação em }\end{array}$

Antropologia

vol. $16(1) \mid 2012$

Vol. $16(1)$

\title{
Categories are alive: interview with Brackette F. Williams
}

By Susana Durão and Cristiana Bastos

\section{Susana Durão, Cristiana Bastos and Brackette F. Williams}

\section{(2) OpenEdition}

Journals

Electronic version

URL: https://journals.openedition.org/etnografica/1438

DOI: 10.4000/etnografica. 1438

ISSN: 2182-2891

Publisher

Centro em Rede de Investigação em Antropologia

\section{Printed version}

Date of publication: 1 February 2012

Number of pages: 187-200

ISSN: 0873-6561

\section{Electronic reference}

Susana Durão, Cristiana Bastos and Brackette F. Williams, "Categories are alive: interview with Brackette F. Williams", Etnográfica [Online], vol. 16 (1) | 2012, Online since 21 May 2012, connection on 12 February 2022. URL: http://journals.openedition.org/etnografica/1438 ; DOI: https://doi.org/ 10.4000/etnografica.1438

\section{(c) (†) (8)}

Etnográfica is licensed under a Creative Commons Attribution-NonCommercial 4.0 International License. 


\section{Categories are alive}

\section{Interview with Brackette F. Williams}

By Susana Durão and Cristiana Bastos

Brackette F. Williams is an American anthropologist and a Senior Justice Advocate, currently an associate professor of Cultural Anthropology at the University of Arizona. She studied at the University of Cornell, the University of Arizona, and received her doctorate from Johns Hopkins University. Her work interweaves matters of race, gender, class, ideology and politics in a unique manner - as seen in the article "A class act: Anthropology and the race to nation across ethnic terrain" (Annual Review of Anthropology, 18, 1989), the innovative monograph Stains on My Name, War in My Veins: Guyana and the Politics of Cultural Struggle (Duke University Press, 1991), and the edited volume Women Out of Place: The Gender of Agency and the Race of Nationality (Routledge, 1996). She is also the recipient of the MacArthur "genius" award, aimed at helping "creative people to improve the human condition”.

Over the last years, Brackette Williams approached multi-racial communities with an original interpretation of the theory of social conflict. Her forthcoming book Classifying to Kill: An Ethnography of the Death Penalty System in the United States, based on ethnographic work, addresses the death penalty schemes as a classification process for making concepts and categories designed to objectify the dynamics surrounding the death penalty. Williams examines how the ways to kill, present in the contexts and debates of death penalty, influence and display social ideas about revenge, retribution and punishment. She argues that those categories "fight with each other" all the time in order to define justice in America, a country in which ideas and practices about race, class and gender present in informal practices join those in the formal legal system.

Brackette Williams shares with us some biographical memories, finding in the past the ground for her alternative and provocative view for Anthropology: "I never thought of our life as good or bad. It was just something we did", she said of her migrant worker family. "But I was very much aware of how certain ethnic groups were treated; how some were punished for speaking Spanish, how some flowed in and out, while others never could. And I was very much aware of power, the power the white managers and landowners could hold over others. I don't think it is at all necessary to have lived that kind of life to become a good anthropologist, but I do know that I have been conscious of those issues all my life" (<http://www.jhu. edu/ gazette/janmar96/feb2696/26brack.html>, November 2011).

DURÃO, Susana (ssbdurao@gmail.com) - Instituto de Ciências Sociais, Universidade de Lisboa, Portugal

BASTOS, Cristiana (cristiana.bastos@ics.ul.pt) - Instituto de Ciências Sociais, Universidade de Lisboa, Portugal 


\section{A HAPPY OCCASION GAVE US THE CHANCE TO HOST BRACKETTE} Williams at the Institute of Social Sciences, University of Lisbon, as a speaker at the conference "What is racism, after all? Transdisciplinary perspectives", 8-9 March 2010, organized by Ângela Barreto Xavier, Cícero Pereira and Susana Durão. We took the opportunity to hear Brackette's new ideas on why "categories are alive".

SUSANA DURÃO Let's start with the simplest question of all...

CRISTIANA BASTOS ... what made you an anthropologist?

BRACKETTE WILLIAMS That's a simple question? Well, I didn't start out to be an anthropologist. I was interested in physical science. I was doing Human Development and Family Studies and I then became interested in Anthropology, after I returned to spend a year at Cornell and audited a class with Thomas Gregor in wich we read Clifford Geertz's Thick Description. We read his [Gregor's] book, Mehinako, and I thought "Well, this is really interesting", so I applied to graduate school and I went to the University of Chicago, but I still went into Human Development and Family Studies, which was called the Committee on Human Development at the time (because Chicago had those committees). I took more Anthropology courses and decided that I really wanted to be in Anthropology. However, although I wanted to do something outside the United States, I wasn't quite sure where, but maybe the Caribbean. Drexell Woodson told me about Hopkins, which had the Atlantic History and Culture program at the time. So I applied and transferred and that's how I became an anthropologist.

$\mathrm{CB}$ Are there any landmark figures or ideas you would pick out from those formative years?

BW I had been interested in Gramsci but, in graduate school, until I finished my dissertation, I didn't do that much on Gramsci. The only person who was interested in him, at that time, was Katherine Verdery. So I did have conversations about his work with her but the people I worked with were, of course, the Caribbeanists in the department, Rich Price, Sidney Mintz, but more Emily Martin, who was a Sinologist at that time, and Kathy Ryan, who was just finishing her PhD from Cornell when she got the job (she worked in Sri Lanka). Those were the people I worked with, and Philip Curtin and John Higham in History. So I really was trying to stay within what the program was supposed to be, Atlantic History and Culture, and I really did want to learn a historical approach to Anthropology. And I ultimately believed what I considered was the anthropological creed at the time: that you took a detour through the other in 
order to come back to study the self. My intent was always to come back to the United States, but I wanted to get away, do something, see something. This something would help me to make more visible that which was, in some ways, ultra-visible in race relations in Sociology. But I knew that wasn't the way I wanted to look at it. I just didn't know how I wanted to look at it. So that was getting back, doing the detour, going someplace else and coming back.

CB What would you say you brought to the wider community in terms of understanding/awareness of social issues?

BW Well, I don't know what I've brought to the "wider community". I did what I intended to do. At the time that I entered Anthropology, at its core were kinship and social organization which, essentially, were classification systems that floundered on the limits of typology. So, "Let's jettison all that stuff: no social structure, no social organization is ever going to have a set of clear-cut principles that will give you a stable taxonomy". So it's, kind of, out the door with that.

But that's what I got from Anthropology in terms of my detour, and so I came back to the United States after the work that I did in Guyana, which was trying to refine and hone the conversation that takes place among categories. First, people have to embody them, they have to act them out. But I was interested in the conversation among categories because I thought that was a better way to try and understand race and the racial predicament in the United States, rather than the political economy of it even. There is a way in which categories just start talking to one another and you don't have a human conversation going on anymore. And I think in Guyana I found that conversation. It had had some bloody results, but it was calming down at that time. But it was still very much categories and concepts talking to one another, embodied, walking, talking, even sometimes boogying and having a good time. Everything was categoric identity, categoric thought, and I thought, "This place is really, really wonderful!"

Could you give us an example?

BW My favorite example is going to the rum shop, the soda shop, to buy soda, and I would buy red pops. The red pops were Indian's and so I was told I was biased against black men. It was a bit of a joke, but it wasn't a joke either. We know what joking is and the power of joking. So it was being told I wasn't getting my racial categories proper. I wasn't getting my ethnic categories proper. And then I liked roti and that was, well, and the Afro-Guyanese would say Indians do make really good bread, we don't make roti, it is an Indian thing. Everything was pretty much identified by some ethnic category either 
by joking or seriously. I think in the book Stains on My Name, War in My Veins (1991), I described it as walking on eggshells everyday, because you're always trying to figure out where you're at (ethnically and racially). But I think the image I had was that it was an eggshell field but had landmines in it constantly. So it was not just crushing the eggshells. It's being blown away by the landmines even as you tiptoe across the eggshells. And how does one live with that? And that's what that book tries to describe: how and why does one live with that? Particularly since it came out of a history of being manipulated, divided, conquered, and pushed into specialised economic roles; and all of that. And why replicate that, why find some positive value for its meaning? It was a mystery, but it was a mystery that was very much the mystery I needed to engage in, I thought, to come back to the United States.

So the fact I didn't continue to engage in Guyana probably didn't surprise me. It might have surprised other people, but... I had a mission, and I had to figure out where next to locate that mission. I tried for a minute doing AfricanAmerican Studies but that really wasn't going to be a core for me because that was kind of living within the categories. It was becoming that which I had just studied. I have nothing against the politics of that struggle: it is a necessary struggle, it is one of the trenches you get in to find where the velvet glove is that's going to punch you, and then you go on. But I was looking for something, and that something I knew was going to be classification.

So when I got the opportunity to do research on my own I did it, classification. I'd applied for a couple of grants. One I got to go to India. I was going to try and look at comparative caste: caste and furnishings and some of the other stuff people were writing on castes and the changeability of caste rather than its fixedness: between the way castes can work as status rank, can act like class - can act like these other kinds of things, and maybe was some of these other kinds of things. I was looking for the nexus of classification systems. I wanted several classification systems sort of dancing together and I wanted to be able to find the nodes, the nexi where they were linking together, where the flow of criteria was moving across different kinds of grids. And so, ultimately, I found that in the United States post-Furman death penalty, and so that's what I ended up working on.

SD Could you also tell us more about the text "A class act..."?

BW Well, "A class act..." was a funny thing because I had written the conclusion to Stains on My Name, War in My Veins..., which took a while to get published, in 1991. I was asked to write a piece for the Annual Review on the concept of ethnicity (I believe that was what I was asked to do). And I realized I could not write about ethnicity without writing about race, class, gender and nation. And so, that was where the title came from. I wanted to see the flow 
of criteria but I decided to make Anthropology the object of the flow. So it became Anthropology and the race to nation across ethnic terrain, it became Anthropology constructing itself as it moves across these categories. That was what I was trying to say in that piece. At the same time, I was trying to produce a framework for myself, to be able to move forward from that as soon as I could find another object of investigation. And I tried race-class-gender again, but the truth was I thought I had gone as far as I could go with race-classgender. There was too much of a blinder there for me. I needed something that was just completely different from me, you know, that had race-class-gender in it; that had age in it. I wanted age in there but I didn't want to go and study the elderly per se. I wanted the age spectrum, not just one little piece of it.

So there it was, the death penalty: a beautiful, beautiful thing to study. I know that's a sick, perverted kind of thing to say, but it is a truly beautiful thing. You have forty classification systems, with intellectual legal histories, within a history with, as [Michel] Rolph [Trouillot] said, its various kinds of silences for race-class-gender and all these things. But it's all these social classifications coming into law that (ironically) are going to construct this wonderful, fabulous objectivity - so that you can select just the right person to kill. It didn't get better than that! I mean, honestly, there were bifurcated emerging kinship systems. Here was one that was all about picking people to kill them. That was an anthropological dream for me, and so off I'd go. But we will see whether I succeeded in any respect. The long version of the book couldn't get publishers: bad for marketing.

\section{SD Too big? Enormous?}

BW Yeah, it was running on to a Malinowski-sized Coral Gardens and Their Magic (the truth of the matter is that it was twice the length of the published Coral Gardens and Their Magic!). So that was going no place and I knew it. But it was necessary to write the thought. After almost twelve years of data gathering, it was necessary to write the thought and then when the thought is finished, break it into little ideas or little pieces of ideas. So what is coming out is a piece of the piece. But it is the piece about the classification system, about all of the classification systems flowing into one another, trying desperately, I mean, seriously, to make objectivity.

That is a funny thing, because we all already know you can't make objectivity, rather you can make all kinds of objectivities - just get enough people in a room. You can make rationalities; lots of them. But can you make objectivity and rationality stable enough to kill for... or kill with, actually? Kill with. And so that was the task. It was conducted with a twelve-page questionnaire, but I had one question: can you do it? Can you stabilise the core of concepts long enough to get them into position, to keep them there, to produce the binaries 
you need, to get the tertiaries into place, to level, to branch and hold on to it long enough to create a person and kill it (or not kill it)? That's all.

\section{SD To decide.}

BW Yeah. To decide and to say you have done it objectively and rationally. That you have got rid of the nasty booger called subjectivity, the human factor, prejudice, bias, all these other concepts that parade under unacceptable levels of subjectivity. And, well, I'll let the book tell you whether or not I managed to show you that. But that's what I was out to show people. And talking to informants: "Isn't that racism?" "Yeah, come on, but what is race here?" What's the core? At any given moment, you can look and you can ask yourself: what are the core attributes of the concept of race? And that statement, from that person, doesn't it over-represent race? Why are you asking me, and what kind of construction of race do you have that lets you say that? What are the politics that are driving the leveling and branching of the politics of a class in a daily order? So there I was...

CB Who did you interact with (while writing the book)? Who were your interlocutors?

BW There was the legal and activist community. It turned out that activist communities all, kind of, fit under what became known as the Social Justice Reform Movement. But in that, some people were trying to reform it to be more draconian. And there were people that were trying to reform in the other direction. So "reform" was one concept that one had to get at. The next one was "participate". I spent, I don't know, about a year and a half just on the concept of "participate".

And so, if you ask me who my informants are, I would start with police officers on the street, police officers in county jails, city jails, correction officers, going back and forth between prosecution and defence, sitting in on trials, talking to judges. All the way up to going, finally, to the United States Supreme Court to hear "Ring versus Arizona" because there was the judge classification system, where the judge made the decision. And there were different ways in which the judge made the decision. Sometimes, it was just the judge in the second trial that would make the decision. Sometimes it was a judge panel, sometimes it was by judge override (the jury would make the decision but the judge could review it). Then states had their high court override or review, as it was called. You just kept going up and down the levels, and went wherever a particular case you were working on to see what the classificatory dynamic was that got it there. Then, of course, there was the effort to help people not get sentenced to death when they had been capitally charged. That was the whole mitigation process 
of looking at the concepts that were being drawn in, to pull from them attributes to make mitigate. So what kind of thing could you bring in to make a person a mitigatable being? And then I wanted to see the way in which that mitigatable being, which I call the categoric person, displaced the messy individual for the objectivity and rationality that was needed. But if the individual got too clean, then it wouldn't fit very many cases any more and mitigation would become more and more narrow.

So you had to be able to open it up. We all know classification systems have an open end. They are open on both ends. But the morality of the two ends is not the same. You can follow concepts in terms of which end they come in, you know, the "anything else" pool, as the law was saying, the "Anything else that will call for mercy". Well, there was that open end. The other one was "Don't let this person get away with what ought to be capital murder". So can you get what were called "the aggravators"; can you get enough of them to pull in all the kinds of things you want to pull in? There was that open end as well. So it was a wonderful experience, it was an amazing system that I could not have written a proposal to study. That's the other piece of this: getting there through McArthur and being able to just play cognitive detective, basically. So I just kept adding to the questionnaire, you know, different levels: "So you're doing this now, so you can get off the streets, you can go into the courtroom".

And finally, all the way through to watching witnesses watch the execution. Then you think that's the end but no, there's the burial. Who gets the body? How do they get the body? How do states differ in terms of the classification of the state's stain that is on the body? That becomes a construction of the history concept: are we that backwards still? So that feeds into the notion of the maturing society: do we still hold onto somebody's loved one? Is it a loved one?

There's the whole victim politics that is going on in there. In fact you can compare the construction of the positive and negative valence of the victim concept for crime victims with other kinds of historical victims, like race victims, gender victims and, of course, there are race- and gender-crime victims. So you pull in these different modes of constituting a being by the victimization of adversity, suffering, pain; that make breaks in time. And, so the concept of time becomes very big because it's being constructed for efficiency, speed, you know, get them in, get them out, get them on, get them on to the execution, speed of execution: whether you hang them, stick them, shoot them... Time is a very busy concept in this process, you're constantly figuring out ways to go and look at time get constructed, talking to people about what they're doing with a concept of time.

CB Who did you talk to about your concepts? Or were you by yourself? 
BW I was telling everybody about them. I had some of my anthropological friends still, by this point, because some of them were upset, saying "Oh no, you are working on the death penalty! That's just horrible! Aren't you miserable?", "How do you keep your head together?" The fact was that I was having a good time, but I was feeling really bad about it. I'm not a supporter of the penalty. I didn't want people to be killed. I didn't care what they'd done. But, at the same time, that wasn't where my head was, and so there was the constant schizophrenia of it: talking to people about that, being willing sometimes to talk the politics of whether or not "victim" ought to be the leading concept for having the qualifications, the moral qualifications, to do that ("Because I had a murdered brother", that sort of thing).

Anthropology is an opportunistic discipline, let's just face that. It is sometimes ugly.

\section{SD Opportunistic in what ways?}

BW It is just opportunistic. I was talking to lots of people, but anthropology is also reciprocal - all this "rapport building" stuff is another word for reciprocity. You should give something back, and I don't mean it in some hokey kind of way, because it is still opportunistic. You are staying in the community; you are in people's faces; you are getting them to tolerate you; they're spending lots of time and energy explaining to you: "Yes dummy, we do that, too". And so I gave some talks, I did a lot of volunteer work, stuffed a lot of envelopes. And then, in my opportunistic way, I was on steering committees. I was doing the inside view of several concepts I was interested in, but I was also entering the strategy of the activist group. Therefore, I wouldn't be on a steering committee of a group whose actions I didn't believe in. I would find another methodology for engaging them, but I would talk to them, of course, I had to.

So I engaged people in different ways, which is why I think I probably have a problem with the idea of being defined as an engaged anthropologist in that sense. I engaged as an anthropologist. I engaged as a citizen, but when I engaged as an anthropologist that was not necessarily a politically advanced thing, it was sometimes pretty retrograde and opportunistic, let's say.

I was on the board of the ACLU (American Civil Liberties Union). I did my job while I was on the board, but my reason for running for the board was because I wanted to see how it was operating inside, and I didn't lie about that. I wanted to see and I asked lots of questions that had nothing to do with what was going on at the board meetings, and I recorded it. I tried to be upfront about as much as I could without distorting information I was trying to gather. And where I wasn't absolutely upfront I wasn't going to use anybody's name. And so the book is about concepts, it's not about people in that 
sense. Of course, you can't have an ethnography of concepts without people being in your book too, but the book is about the concepts.

SD But did you suffer a bit with all that ambiguity? Be honest...

BW Did I suffer? That's a big concept, suffering [laughs]. Did anything happen to me that was worthy of applying the concept of suffering to me? I'd have to say no, given what was happening to other people. Tired sometimes, yes, worn out, feeling really at the limits of "Where do I go next?" But then it was the usual anthropological thing, "I know all this stuff now. I'm really tired of this. Let me stop doing field work on this subject and then maybe I'll do something else. Report something for my grant, oh, oops! The five years are up! Gone!..."

So no, I don't think I suffered. I think I was tired a lot because I'm obsessive and given that I had nothing else to do, just research. I was being paid to think, that was all I had to do. McArthur wanted you to think and be creative all the time. So that was what I was doing. And that gets to be very tiring, very boring, but suffering is a little bit extreme.

Watching an execution, I'm sure that's not fun, but you put yourself in a position and so you don't play anthropological hero. I chose. I'm watching people watching something that is tremendously powerful for them. So I am not horrified, except by my own callous immorality and that did get to me at times. "Can you really be thinking you are going to do that?" Well, let's look at it. What are the methodological options? And people would say "How can you talk to people who kill people, you know, executioners?" Well, how else am I going to understand how they understand what they are doing if I don't ever talk to one? That's not going to work!

I tried to explain to people what I thought Anthropology was and what Anthropology does in the world. For what I still very much believe, it is the detour through the other in order to study the self, and as an African-American woman, who's myself, that's one of those complex problems.

Nonetheless, this is the place where that problem began for me - that place over there that had those forty nice little schemers trying to kill people. That was the place that made me and the problem of what it is that I am. So that is the place I had to detour back through in order to see the relationship between the grand theories of the human, the South of the United States, and the social dynamics on which that South was produced and had to exist. I wasn't going any place. I wasn't Josephine Baker, so I wasn't going to go dance in Paris. I was going to be in America and so I had to figure out how I was going to be American. And that meant trying to figure out what is America (or as we came to call it, "US America" so we didn't steal the whole continent every time we opened our mouths; but that didn't last long and it's back to "America" now). 
SD After your experience, do you look at America the same way as before?

BW I had a pretty ugly view of it to begin with, but now that I can substantiate it, I can understand the dynamics of it. You know, you fear ignorance, or you fear the unknown, I'm told. I don't know that I have ever been that fearful of the unknown. As in Anthropology you are constantly running after it, I don't exactly see how that can be true. You are constantly running after the unknown. Anything you don't know, you are trying to get your hands on it, get your mind around it, trying to invent things that you don't know. In case you don't want to go any place to study anything, you can sit around and invent something you don't know.

For me it's all about knowing. So it is knowing things that I didn't know but I suspected, that I could make nasty defamatory statements about, which I couldn't really prove. But I think I can now, I can prove some things. I don't feel any worse about America now than I felt about it to begin with. I don't dislike it any more. What I disliked about it, I still dislike about it. What I wanted to change about it, I still want to change. If I figure out a way that I might be able to do that, or let's say, if I encounter someone who seems to be doing something that I think might change that, I try to join them. And when I figure out whether or not I think they really are or not... I drop in and out, I'm kind of fickle in that regard.

SD You told me before that people seem to be trained not to think, the students...

BW Yes, students don't think. You're not trained to think. I don't really want to knock too badly political correctness, not to think is a way to know what to say. And by knowing what to say, to have it appear that you know what to think.

What I came to refer to as I was in the middle of my field project (I'm not even sure whether it stayed in the book or not), it is certainly the core of a translation of something that comes out of Gramsci for me; "studied stupidity". When I was in my second or third year of graduate school, I defined Gramsci's notion of culture as studied stupidity: that you had to learn to be stupid enough to get on with doing what you had to do at that particular moment. And so there wasn't any counter-hegemony, and it wasn't false consciousness because you could know what you were doing.

You see, I didn't like Marx because you didn't know what you were doing and you were doing it anyway. I didn't like that. I wanted you to know what you were doing and do it anyway because it was the only thing that you could do. So, having the terrain on which to struggle, and struggling there knowing that this is really a stupid terrain, thinking “But I really can't afford to think about 
that too much, because I won't get off this terrain ever and get into the next ditch and the next ditch behind that and figure out who else's fist is wearing the velvet glove..." You don't get any place that way. You have to be stupid to some extent. But we've gone too far, I mean, we really are stupid!

SD That's the story of bureaucratic thinking in a sense: functionality.

BW It is; it is. But I think that the kind of thing that I was discovering with looking at the death penalty from the standpoint of classification dynamics is that kind of cultural environment. When I read Geoffrey C. Bowker and Susan Leigh Star in Sorting Things Out [The MIT Press, 2000] and they said "We live in classification society"... I remember anthropologists used to call that "cultural tyranny" when it was about the natives - they've got to follow all these rules and culture dominates.

CB About ourselves...

BW Yeah! That's it. So cultural tyranny has come home to roost, it's not just the colonials that are coming home. So you start going back, reading Max Horkheimer right after the war and he was talking about the trends towards this kind of objectification, to compete with positivism and all that kind of good stuff. See for instance, the Critical Theory [Horkheimer, O'Connell and Aronowitz, Continuum Publishing Corporation, 1975] or, recently, the Eclipse of Reason [Horkheimer Press, 2008].

CB Do you think that Anthropology is developing towards a resolution of these complexities, or is it getting further away?

BW I think we are getting further away. Well, with the anti-canonical Anthropology there is no discipline. We don't have to stay within disciplinary boundaries, we can be interdisciplinary (I think the idea of telling Anthropology to be interdisciplinary is another one of those studied stupidities because you cannot avoid being at least disciplinarily promiscuous). You have to have a little bit of History; you've got to see what the psychologists are up to, because they are the ones messing up your individuals in most societies. I mean, some of the individuals are doing it themselves, but individuation is different from individualism.

As anthropologists we have to engage the other disciplines to see what they're up to because they're making the human make itself. And you are going to study the human making itself, so how can you not pay attention to what they are doing? But you don't have to become one of them. That's like going native if you start buying other people's theories too much. And that to me 
just felt a little bit too much, like going native rather than bringing the natives home to roost, which is what I thought we were trying to do. With that sort of detour the self that you bring back home isn't supposed to be the self that you trucked out to the field with. So what's the point?

So we brought back what we should from these other disciplines but we felt we didn't want to do that because we had these subjects that we were bored with. We were bored with kinship and social organization; we were bored with taxonomies. They were our "butterfly collecting" as Leach said. Well, that was true! But the death penalty was butterfly collecting. And it wasn't just pinning them to the mat. It was sticking a needle in them and killing them. It was still butterfly collecting, he was absolutely right, but it didn't go away just because we figured out that typologies were always unstable. In fact taxonomies are always cutting off half of the world in order to make themselves stable. We are in a binary world, a constant movement between binary oppositions and creating tertiaries. So I still read the Edmund Leach book, Political Systems of Highland Burma [Berg, 1973], not for the same reasons I read it before, but now I read the Gumsa and Gumlao communities in a very different way. In fact, I read almost everything in Anthropology in a different way. But I still read Anthropology. I always find Anthropology the place to start and then go out and see what the other disciplines are doing; what comes back from them.

SD Now we see a lot of people doing a kind of philosophical Anthropology, don't you think?

BW Yeah. Probably, if you look at my bibliography it may appear that I'm lying, because I don't know how much Anthropology is actually cited in the bibliography of this book! But that's because that bibliography is also a bunch of natives. You know, the neuroscience people, the other people that you had to read, that you bring into it. But the frame, the question, the project itself is, I think, hardcore Anthropology. And that's why I had to read the Anthropology upfront: to figure out where I was at. But reading these other disciplines I came upon different concepts that they were dominating or controlling or being pulled into law, or pulled into various political action groups that were under this umbrella of "social justice rapport".

CB And as a last question: what is race to you? Would you like to share your views on this issue and on what we have seen and heard today [in the seminar "What is racism after all?"]?

BW I think that, in every location, in every historical moment, particularly in the market-driven academy, we reinvent the wheel as a studied stupidity: "We don't know this for Portugal", "We don't know that for Italy", etc., etc. 
On the one hand, you're building theory, but theory never travels as such. On the other hand, we can write about travelling theory. So we do more writing about travelling theory than we do actually apply theory as it ought to travel in a comparative effort at the holistic analysis of anything.

Here we are in Europe and Europe is discovering the new world, but the new world has been there, and it was there in that original discovery. So there is a great deal of work in the Caribbean region and Latin and South America, where these issues have been engaged for a very long time. I didn't see here much influence from there, and I think that's somewhat disappointing. For me, this event was an opportunity, I think, to bring together the classification stuff we have been talking about. It was the next step in saying "What is race after all?" Race is a problematic concept. Not because it can't be stabilized like any other concept, it isn't a bad, nasty concept that can't be thought properly. It's not thought properly because of studied stupidity.

We don't want race to contribute to the construction of the concept cause. And that was the point I was trying to get across with the focus of the data I was using: that concepts became unstable and useless and analytically worn out because of the politics of that decision, not because the concept is cognitively different. So what is race after all? Race is another concept in an arsenal, wich has been particularly battered because we don't want to think about race in relationship to class either. We don't want to think about the way its attributes flow across a classification system.

So, if you start anywhere in a classification system, with a concept that is going to move you in a direction you don't want to move, you lop off that concept, you try to lop it off, you try to block the flow. Therefore, you just pick on that poor little concept until it is bloodied and then you go on to the next one. But you can count on the fact that a concept will come back, just as there are now articles about the "return of the State", the "return of the citizen". Those concepts are also going to be in big trouble, because if race becomes invisible and they take it in that space of causality then they are also going to become problematic, and they're going to get brutalized.

So, what is race after all? Race is a scapegoat concept for all the other concepts that we now want to treat nicely. We'll send race out into the wilderness of studied stupidity and we'll pull in all these other concepts. Class is back and we've really got to get down to root causes and political economy. It's really sexism, and it's homophobia, and it's anything that's nice and sexy at the moment (I didn't mean that, you know... You know what I mean! [laughs]).

But where is race after all? Race is a concept, and therefore it is part of a power dynamic, just like any concept. It can be exceedingly evil, it can probably be good. I think that concepts are the history of the accreted meanings. So you don't have absolute flexibility... The idea that you can culturally construct 
anything; yes you do, everything is culturally constructed in the sense that everything is cognitively constructed. However, it doesn't mean you can eliminate the history of a concept. The dictionaries have it all hidden right there on the pages, but in case you don't look in the dictionary, these meanings are still out there; out in the world.

They are cognitive concepts, I mean, concepts have lives, and they live those lives and you can't just say, "Oh, you're brand new, I just gave birth to you". You can pretend that you did, but that's not going to be true. You don't have that kind of freedom. Some of them are really old and grey and bent, just hobbling along, others are for the moment sprite and spry. I think some of them are taking Viagra [laughs].

SD You have showed us a kind of love for your concepts.

BW Exactly. Give them all Viagra as they're going. You are giving Viagra to some and the others, well, you're poisoning them, you give them a shot of belladonna! 